\begin{tabular}{|l|l|l||}
\hline \multicolumn{2}{|c|}{ PublisherInfo } \\
\hline \hline PublisherName & $:$ & BioMed Central \\
\hline \hline PublisherLocation & $:$ & London \\
\hline \hline PublisherImprintName & $:$ & BioMed Central \\
\hline \hline
\end{tabular}

Neuronal pathfinding
\begin{tabular}{|l|l|l||}
\hline \multicolumn{1}{|l|}{ ArticleInfo } \\
\hline \hline ArticleID & $:$ & 3664 \\
\hline \hline ArticleDOI & $:$ & $10.1186 /$ gb-2000-1-5-reports 0075 \\
\hline \hline ArticleCitationID & $:$ & reports0075 \\
\hline \hline ArticleSequenceNumber & $:$ & 18 \\
\hline \hline ArticleCategory & $:$ & Paper report \\
\hline \hline ArticleFirstPage & $:$ & 1 \\
\hline \hline ArticleLastPage & $:$ & 4 \\
\hline \hline & & RegistrationDate $: 2000-10-4$ \\
ArticleHistory & $:$ & Received $\quad: 2000-10-4$ \\
& & OnlineDate $\quad: \quad 2000-10-25$ \\
\hline \hline ArticleCopyright & $:$ & BioMed Central Ltd2000 \\
\hline \hline ArticleGrants & $:$ & R \\
\hline \hline
\end{tabular}




\begin{tabular}{|l|l|l|l|}
\hline ArticleContext & $:$ & 130591155 \\
\hline
\end{tabular}

\section{Joe Hao}

\section{Abstract}

Motor neuron identity and target selection are primarily genetically controlled.

\section{Significance and context}

Different subtypes of motor neurons not only display characteristic properties of cell migration and axon guidance, but also express unique combinations of LIM homeodomain transcription factors that may act as intrinsic regulators of these processes. For example, the MMCm (medial half of the median motor column) motor neurons, which innervate axial muscles and express the LIM genes Isll, Lhx3 and others, occupy a ventral position in the spinal cord and project axons to axial muscles. However, the PGC (preganglionic motor column) motor neurons, which do not express $L h x 3$, migrate to settle along the intermediolateral edge of the spinal cord and project axons onto sympathetic neurons.

Although studies have shown that displaced motor neurons project to the appropriate targets, the axons of neurons in a completely novel environment often passively follow the axonal pathways in that region. It is therefore apparent that both intrinsic and extrinsic mechanisms contribute to proper motor neuron connectivity, but little is known about their relative contributions in controlling target selection. Sharma et al. show that forcing all motor neurons to express the MMCm-specific LIM gene $L h x 3$ is sufficient to convert their cell migration, gene-expression profile, and axonal projections to that of the MMCm subtype of motor neurons. Despite the strong correlation between LIM gene expression and motor neuron identity, elevated occupancy of the $\mathrm{MMCm}$ axonal pathway can override the genetic program, causing some $L h x 3$-expressing axons to project to other targets. This suggests that environmental factors may also regulate target selection.

\section{Key results}

The authors converted all motor neurons to an axial-muscle-innervating MMCm identity by ectopically expressing $L h x 3$ under the control of a pan-motor-neuronal promoter in a transgenic mouse line. In these ectopic $L h x 3$-expressing embryos, $L h x 4$, another LIM gene normally found only in MMCm motor neurons, was expressed by all motor neurons. Likewise, markers for other motor neuron subtypes were downregulated. These results provide strong evidence that $L h x 3$ expression is sufficient to drive all motor neurons to display the molecular attributes of MMCm cells. 
Motor neurons that normally do not express $L h x 3$ and do not reside in a ventral position in the spinal cord, such as the PGC neurons, did so in ectopic Lhx3-expressing embryos. The PGC motor neurons failed to migrate to the intermediolateral edge of the spinal cord, and instead were found intermingled with MMCm motor neurons, consistent with the notion that Lhx3 expression confers the MMCm identity.

Finally, the authors examined the axonal trajectories of motor neurons in embryos expressing ectopic Lhx3. They predicted that all of the neurons would project to axial muscles, the target of the MMCm neurons. However, while most of the axons did innervate axial muscles, some followed the normal pathway to sympathetic neurons. This suggested that either the altered genetic program in these motor neurons is insufficient to direct all axons to axial muscles, or that some extrinsic mechanism limited axial muscle innervation. The authors tested these possibilities by creating lines of mice that contained different mixtures of wild-type and ectopic $L h x 3$-expressing motor neurons. These chimeric embryos were then analyzed for the number of $L h x 3$-positive axons that did not innervate axial muscles. Interestingly, the number of neurons that did not project to axial muscles increased as the number of Lhx3-positive neurons in the chimera increased, suggesting that elevated occupancy of the axial pathway influences the trajectories of other motor neurons that would otherwise project to the same target. This shunting of axons from heavily innervated axial targets reveals an epigenetic interaction that is capable of overriding the genetic program in these neurons.

\section{Conclusions}

The authors conclude that the genetic program of a motor neuron is critical for the regulation of its migration and target selection. However, it is not the sole determinant, as an axonal pathway that has reached a threshold occupancy is by-passed by axons of motor neurons that would normally project there. They speculate that this 'exclusion' mechanism acts as a barrier to prevent inappropriate axons from entering, and may cooperate with axon guidance receptors to achieve specific motor neuron-target connections, increasing pathfinding fidelity.

\section{Reporter's comments}

The results show that LIM homeodomain transcription factors regulate the development of the proper topology of motor neuron subtypes in the vertebrate spinal cord by coordinately controlling cell migration and axon guidance. Thus, the decision to express specific LIM genes and downregulate others is a crucial step in motor neuron specification. Although this conclusion may have been anticipated, what was unexpected was the ability of an axon's environment to override the genetic program laid out by LIM genes. These findings support the notion that motor neurons use an intrinsic mechanism as a primary means of dictating identity, and both intrinsic and extrinsic mechanisms to regulate target specificity. These studies provide a compelling insight into the means by which the combinatorial expression of genes influences neuronal fate. 


\section{Table of links}

Nature

References

1. Sharma K, Leonard AE, Lettieri K, Pfaff SL: Genetic and epigenetic mechanisms contribute to motor neuron pathfinding. Nature. 2000, 406: 515-519. 0028-0836

This PDF file was created after publication. 